\title{
Toward a Learning Technologies Knowledge Network
}

Roy D. Pea, Robert Tinker, Marcia Linn, Barbara Means, John Bransford, Jeremy Roschelle, Sherry Hsi, Sean Brophy, and Nancy Songer ${ }^{1}$

To appear in Educational Technology Research and Development, 1998.

\begin{abstract}
The NSF-funded Center for Innovative Learning Technologies (CILT) is designed to be a national resource for stimulating research and development of technology-enabled solutions to critical problems in K-14 science, math, engineering and technology learning. The Center, which was launched at the end of 1997, is organized around four themes its leadership has identified as areas where research is likely result in major gains in teaching and learning. The Center sponsors research across disciplines and institutions in its four theme areas. It brings together experts in the fields of cognitive science, educational technologies, computer science, subject matter learning, and engineering. It engages business through an Industry Alliance Program and is also training postdoctoral students. CILT's founding organizations are SRI International's Center for Technology in Learning, University of California at Berkeley (School of Education and Department of Computer Science), Vanderbilt University's Learning Technology Center, and the Concord Consortium. Through its programs, CILT seeks to reach beyond these organizations to create a web of organizations, individuals, industries, schools, foundations, government agencies and labs, that is devoted to the production, sharing and use of new knowledge about how learning technologies can dramatically improve the processes and outcomes of learning and teaching. This paper describes the rationale and operations of the Center, and first year progress in defining a set of CILT partnership projects with many other institutions that came out of our national theme team workshops.
\end{abstract}

\section{Introduction}

Federal research and development has for several decades contributed substantially to our understanding of how to use information technologies to improve learning. New knowledge provided by cognitive, social, and learning scientists, computer scientists, and subject matter specialists studying learning has generated advances in our understanding of learning (e.g., Greeno, Collins, \& Resnick, 1996). These developments have also led to new architectures for interactive learning environments, and widespread recognition of the shaping roles of social context, motivation, and teacher knowledge in determining whether learning technologies have their desired effects (e.g., OTA, 1995). The most exciting results indicate that we can use

1 Roy Pea and Marcia Linn would like to thank the Spencer Foundation for support during their year at the Center for Advanced Study in the Behavioral Sciences, Stanford University, in which they developed the CILT concept with the other authors. CILT is funded by National Science Foundation grant \#CDA-9720384. We would also like to acknowledge contributions to this article by the many authors of CILT partnership project proposals, and by theme team leaders. 
technology to revolutionizes learning and provide discontinuous rather than incremental improvements in education (e.g., PCAST, 1997). Young children can learn subjects thought well out of their reach (such as calculus learning by inner city middle school students). Technology can support learning outside of school (as in collecting scientific data in the field using hand-held computers).

Results like these are largely fragmented, difficult to find and track even for research specialists in these fields, much less those who could use such knowledge to powerful effect. Commercial learning technology products are largely developed without awareness, much less use, of these research developments. Similarly, research groups in universities often fail to use new developments from industry (e.g., component software and groupware.). How can learning technology innovations be fostered, and scaled at a national level? How can the engines of change that computers and information networks represent be turned to knowledge networks for fostering learning technology invention, testing, use, refinement, and commercialization? The nation needs an integrated forum for building and sharing the wisdom and insights derived from highly diverse sources - university and think-tank-based researchers, industry groups, and teacher knowledge developed through their own innovations and implementations of learning technologies in their classrooms.

The time is ripe for information technologies to make major contributions to improved learning in science, mathematics, engineering, and technology (SMET) at all levels and for all learners. The continued increase of performance in information technology, the huge growth in networking technologies, our increasing understanding of learning and intelligent systems, and the widespread concern for educational quality, standards, and technology utilization are combining to make what could be a decade of educational revolution led by technology (Office of Science and Technology Policy, 1997). Given these expectations, a coordinated, inclusive effort to build an effective learning technologies knowledge network is needed to fully exploit this opportunity because:

- Our work is increasingly complex. Whereas classroom-oriented tools have been the primary focus of previous $R \& D$, we believe that the field must make a crucial transition to focus on ubiquitous access to information appliances by all learners, both in and out of school. This focus means broadening the technology repertoire beyond desktop computers in schools and exploiting diverse digital devices including new "learning appliances," networking infrastructures, and developments in distributed systems for anytime-anywhere learning.

- Broad collaboration is essential. Given this increasing complexity, few projects, institutions, disciplines, or funders can encompass the range of expertise needed to mobilize the combination of new technologies and new insights into learning to identify and solve realworld learning challenges. Achieving major impact requires aggregating ideas and integrating innovations. Innovation must start with an understanding of both educational needs and technological possibilities and be based on technical trends, learning theory, changing school realities, possible marketing arrangements, and dissemination strategies. Close collaboration among a broad range of researchers, industries and schools is the only strategy that can marshal these resources in a timely, effective manner.

- More interaction is needed. New studies of on-line communities conducted for a diversity of industries indicate that the key to new market opportunities and increasing returns is to combine content and communication. Hagel and Armstrong (1997) demonstrate how new 
value is created and captured in on-line communities by providing not only content but also communication and search tools that enable community members to interact and build relationships. There are surprisingly few opportunities for timely sharing of insights and prepublications among potential learning technology collaborators with similar goals but different professional affiliations.

- Field-initiated R\&D needs coordination. The usual strategy of relying on funded fieldinitiated projects to produce educational change needs to be supplemented with coordination provided by the profession itself. Funders can rarely move quickly enough to explore emerging opportunities created by technologies that can now go through two generations in the time it takes to conceive, submit, and award a proposal. These long processing times favor larger grants that then tend to be more risk-averse and, hence, less innovative. Because each proposal is viewed in isolation, field-initiated R\&D seldom forces the selection of a problem's best solution. In result, suboptimal strategies are pursued while promising research strategies requiring sequential grants are difficult to sustain.

In summary, we need to explore flexible, quick, but thoughtful innovations that solve important educational problems and draw from a wide range of expertise. These innovations need to be winnowed and the best shepherded through several phases of development and dissemination, with input from a range of actors and institutions. CILT was established with initial funding from the National Science in order to provide these mechanisms.

\section{Overview of CILT}

CILT is a collaborative of organizations that have come together to create a unique organization to respond to the opportunities and meet the needs described above. CILT has devised strategies and organizational structures than can economically make progress on these huge issues. This section describes the overall CILT structure.

\section{CILT Mission}

The primary CILT mission is to improve science, mathematics, engineering, and technology learning for all learners K-14 through the innovative use of computer and communications technologies. We see the highest leverage through stimulating the development and implementation of important, technology-enabled solutions to critical problems in teaching and learning. Our approach is to engage the collaborative efforts of a wide spectrum of people and institutions. There is the need to coordinate the efforts of computer scientists and engineers, education researchers, cognitive scientists, educators, industry researchers and developers, and subject matter experts throughout the world. We want to attract to education, people from diverse fields and institutions, including those in business, military, universities, and nonprofits.

To accomplish this mission, CILT defined the following objectives:

- Identify areas of high potential. Each year, the CILT leadership reviews and evaluates educational needs and technology-enabled innovations in order to select four general themes and a few specific multi-disciplinary partnership projects in each theme area with the greatest potential for breakthroughs.

- Support rapid innovation. By convening annual agenda-setting workshops for "theme teams" in these areas of breakthrough potential, CILT aims to coordinate and leverage 
developments in the learning technologies field, identify prospects for important multidisciplinary prototype projects, and stimulate others to undertake similar R\&D by drawing attention to targets of opportunity.

- Stimulate collaborative development in selected areas. In each of the four themes identified, CILT convenes meetings and fosters online discussions designed to share ideas and build collaborations between diverse communities.

- Foster widespread research and dissemination. For each theme identified, CILT is reviewing promising practices and selecting the best available technology for support, testing, development, research, and broad dissemination.

- Train new professionals. On two-year cycles, CILT is recruiting, training, and supporting postdoctoral fellows who will be an integral part of high-risk, high-potential multidisciplinary prototype projects for each priority theme team identified.

\section{CILT Leadership, Structure and Strategies}

CILT operates as a consortium of four core founding institutions, with Roy Pea at SRI International serving as CILT's Director, and Marcia Linn (UC Berkeley), Robert Tinker (Concord Consortium), John Bransford (Vanderbilt University), and Barbara Means (SRI International) serving as co-principal investigators. Together they comprise CILT's Leadership Council, and set the Center's long-range goals, select the most promising themes for investigation, and assemble teams to pursue them. These four organizations each bring to CILT a broad range of expertise and an international reputation for making effective and innovative contributions to technology-enhanced learning.

CILT seeks to harvest the brightest ideas and best practices, and to then direct coherent activities toward topics in greatest need of breakthroughs. To marshal the best resources, to obtain crucial input, and to include leaders from many organizations, sectors, and disciplines, we designed CILT as a national effort that relies heavily on invitational workshops and collaboration technologies to make its activities inclusive. The Center's primary work is being accomplished by the mechanism of "theme teams", each of which is contributing to the research and development, communications, training, and evaluation objectives of the Center. The theme teams coalesce insights and initiate new pilot projects that form a foundation for collaborative development through an open but focused process. Theme teams coordinate research, encouraging participants to build on each other's innovations, carry out evaluations and joint research, and critique each other's technological environments. How did we come to the Center's theme team areas?

As a group, our CILT leadership team shares educational perspectives that emphasize the importance of carefully designed activities that engage the learner in appropriating a combination of skills, concepts, and mental models through active engagement in guided inquiry, exploration, challenges, reflection, and communication. Technology can support these learning strategies by providing access to new collaborators, mentors, and teachers; augmenting the range of inquiry with more powerful and intelligent tools; "scaffolding" students as they visualize and model complex situations; and underlying alternative, authentic methods of evaluating student performance. Starting with this analysis of educational and technological needs, we searched for "breakthrough" opportunities where our national collaborative structure could make major contributions. To provide substance to our collaboration, we needed to identify opportunities 
close enough to reality that we could create prototype technologies that can be tested by our colleagues in a variety of real classrooms and other learning contexts. At the same time, the technology must not be transitory; we need to rely on its wide availability and continual improvement over the next decade.

Weighing these criteria and surveying emerging technologies from these educational perspectives, we identified four thematic areas with tremendous potential. They represent our current judgment for the greatest potential for emerging technologies to make major advances in science, mathematics, engineering and technology education. Each addresses an educational challenge, identifies a breakthrough opportunity, and involves potentially important technologies that can be quickly implemented and tested. These opportunities became the focus of the initial four theme teams and are summarized below. Others may evolve in future CILT work.

- Visualization and Modeling. The challenges are that more diverse students need to learn SMET concepts more deeply, just as these fields are becoming increasingly complex. The breakthrough opportunity is that dynamic interactive images based on models may allow broader access to understanding; modeling provides a unifying conceptual vocabulary across the major topics of science and mathematics.

- Technology and Assessment Models. The challenge is that older testing practices undermine efforts to implement new, more powerful ways of learning and teaching. The breakthrough opportunity is that technology can enable embedded, ongoing assessment of developing knowledge and reasoning skills, and support more authentic forms of performance and portfolio assessment activities.

- Ubiquitous, Low-Cost Computing. The ubiquitous availability of computation and networking could have a profound impact on education. The breakthrough opportunity is that the right combinations of inexpensive portable computers, wireless networking, component software, probeware, and learning tools and content software could enable many more learners to engage in deeper levels of inquiry for learning across a wider range of contexts and time frames.

- Tools for Learning Communities. The challenge is that significant innovation in education requires more than a focus on the local process of learning. The breakthrough opportunity is increasing learning through transformations in the social participation of learners in different communities for knowledge building. These transformations may be enabled by network-based collaborative learning tools, multi-user virtual environments and social information filtering. These new connections may also support deeper engagement and ongoing professional development for teachers, and engage disciplinary experts and parents in distributed learning environments.

Achieving deep reform in SMET education requires integrating multiple perspectives into each theme team's work. There are of course cross-cutting issues that we view as important and which we aim to reflect in CILT's project portfolio, including equity, access, and gender (e.g., Chubin \& Malcom, 1996); teacher development (e.g., Shulman, 1987); informal learning; and cognition and instruction. 


\section{How CILT Theme Teams Work}

Each theme team is led by one of the five PIs, and one or two additional co-leaders who have made outstanding contributions to the theme in different disciplines ${ }^{2}$. By linking each team to the core project leadership, CILT can undertake flexible planning and regular resetting of priorities. The theme team structure permits us to realize our goals of stimulating broad, national collaboration, but in a way that is targeted, feasible, and nimble.

Through an annual workshop and on-line discussions, each team surveys educational needs and critically evaluates available technologies germane to its theme with the goal of identifying gaps, overlaps, and priorities for breakthroughs in theme research. Professionals are invited to come to the workshops, share their developments, and look for collaborators. To stimulate collaboration, CILT offers small grants for pilot projects. Project proposals are evaluated according to criteria including concept potential (e.g., innovative and generative; exemplify an innovative, promising instructional framework), leveraging of other resources, involvement of multiple institutions, interdisciplinary teaming, rapid delivery plans, and plans for assessment and documentation of outcomes. Because the resulting collaborations can bring to bear a wide range of human, institutional, and financial resources, CILT is highly leveraged. More than half these funds are intended for researchers outside the founding institutions.

To build community and create a new generation of researchers informed by our community, CILT has a postdoctoral scholar program, coordinated by Professor Marcia Linn, that creates a partnership among recent $\mathrm{Ph}$.D. recipients from the broad range of disciplines represented in the theme teams. Our goal was to attract candidates with a strong mathematics, natural science, engineering, or computer science background. Additionally, we hoped to find candidates with a background or knowledge of learning and education issues. Postdoctoral fellows work most closely with one theme team, but also participate in the core Center functions of conducting the School Partnership Program and cross-theme team research, the Center evaluation, and communication program activities. Each theme team selects one postdoctoral scholar and involves graduate students from one or more institutions ${ }^{3}$.

\section{Summary of CILT Research}

In this section we sketch the orientation and work of the four theme and the pilot partnership projects that have emerged from the theme team workshops and follow-up activities in the first year of the Center. More detailed archives of the workshop agendas, meeting participants, ongoing research project descriptions and URLs, are available from the main CILT Web site, http://www.cilt.org

2 Other theme team leaders include Professors Alice Agogino, Robert Brodersen, and Andrea diSessa (U. California, Berkeley), Jeremy Roschelle (SRI International), and Nancy Songer (University of Michigan).

3 The first group of four CILT Postdoctoral Fellows is still in formation as of July 1998, but includes Sherry Hsi (Ubiquitous Computing), Eric Baumgartner (Visualization and Modeling), and Sean Brophy (Technology and Assessment Models). 


\section{Workshops}

From January through May 1998, CILT conducted a first round of four workshops, one for each theme. We found that the theme team approach is not only viable but was welcomed and found energizing by participants. Invitations to over 1,000 people were sent and more than 300 different individuals participated in the four workshops.

The workshop included five-minute presentations by participants, brainstorming sessions to generate ideas for projects, and discussions of plans for collaborations and follow-up on project ideas. The quick presentations that led off each of the workshops seemed to be very effective as a mechanism for allowing participants to introduce themselves and their work. These presentations stimulated questions that led to rich, informal one-on-one or small-group exchanges afterwards. On-site demonstrations of learning technologies supported collaborative dialogues across ongoing projects.

Participants identified areas of "collaborative need" in each workshop's introductory panels. Full-session brainstorming identified priority issues for research and development; breakout sessions developed synergies across the project groups represented that were later reviewed and elaborated in full-group session. Group leaders identified areas of overlapping findings, areas of diverging findings, and areas of technology, research, or implementation challenge. A central theme for both organized and informal discussions among CILT workshop participants seemed to the matching of areas of educational needs with existing or potential tools and technologies to address those needs. It appeared that the CILT workshops provided a rare and welcome opportunity for many participants to engage in this sort of discussion. Listing and regrouping project concepts on large sheets of paper spread around the walls of a room and of participants voting on the concepts for which they would be most interested in developing collaborations created many opportunities for lively, informal interchanges.

Follow up on collaborations emerging from CILT workshops is ongoing. Typically, at the close of a CILT workshop, 5 to 9 partnership project concepts are identified. Roughly half define a leader, propose a project, and end up leading to successful proposals for partnership projects. Although it is a challenge for workshop participants to continue the discussions and develop collaborations across institutions and disciplines, nearly 20 of these collaborations have produced proposals for CILT or external funding. Twelve partnership projects were funded by CILT in its first year. Many of these proposals involve collaborations among people who had not worked together (and, in some cases, had never met) prior to CILT workshops. Quite a few involve young investigators who are entering into collaborations with more senior researchers in the field. CILT postdoctoral fellows are involved in these different collaborative efforts as well.

Starting in 1999, CILT will combine the four themes into one annual national workshop. This annual meeting is expected to take place in Spring 1999 in the Silicon Valley and in the following year in Washington DC, alternating this cycle in following years. This new format will stimulate CILT-wide collaborations and synthesis, while also fostering theme-team based discussions. 


\title{
Theme Team 1: Visualization and Modeling
}

\author{
(Co-Directors: Profs. Marcia C. Linn, Nancy Songer, Andrea diSessa)
}

Background

This team seeks to create prototype tools that connect promising science models for learners, technological environments for visualization, and intelligent instructional frameworks that help diverse students use these models (e.g., Linn, 1997). This theme team works with other researchers to develop a set of guidelines for adapting professional visualization and modeling toolkits for learners, create prototype instruction that helps students find the best set of models to work with, and work toward a common methodology for evaluating these visualization tools in authentic, diverse courses that encourage students to develop a lifelong habit of expanding, comparing, and refining their repertoire of models.

Visualization tools have revolutionized research activities and communications in science, mathematics, engineering, and technology among university and industry researchers. Researchers can explore and combine images of complex weather events like hurricanes, molecular structures such as pockets on the surface of proteins, or environmental impacts of factors such as deforestation. In the past few years, well-designed tools have enabled students to learn concepts and ways of thinking previously accessible only to experts. Visualization tools can exploit the power of technology to help students understand hard problems like global change, complex system design, or international disease control (e.g., Gordin \& Pea, 1995; Jackson et al., 1996). For example, in the CoVis Project, Roy Pea and colleagues at Northwestern and UIUC have created precollege learning environments for collaborative student investigations using realtime weather data from satellites and supercomputer processing, and archival data and studentcentered visualization tools in the geosciences (e.g., Gomez et al., 1998; Pea, et al., 1997).

Many learners assert that they learn best when they can mentally "see" how something works (Reiner, Pea, \& Shulman, 1995; Russell \& Kozma, 1994). Instruction requires making hard choices among topics, as well as difficult decisions about which scientific models to emphasize when a topic is taught (Hestenes, 1987; Horwitz \& Barowy, 1994; White, 1993). The term "model," in our usage, includes theories, images, and explanations presented in any medium. Exemplars include dynamic animations that model device structures or thermodynamic systems (Forbus \& Whalley, 1994), global warming visualizations that illustrate the earth's energy exchange system, population ecology simulations, and virtual worlds for learning Newtonian mechanics (Dede et al., 1996).

The theme team approach is well suited for work on visualization environments for science learning. First, powerful environments for visualization already exist in university, industrial, and national research laboratories, and may be adapted as pedagogically meaningful versions. Second, success depends on partnerships between experts in technology, science and mathematics disciplines, and pedagogy (NSF, 1996). There are tensions between technological and pedagogical solutions to problems that can best be addressed in partnership. Often, classrooms embrace new technologies without exploring the implications for the curriculum or the learning environment (Linn, diSessa, Pea, \& Songer, 1994). Third, current standard-setting efforts in SMET education, such as the NCTM Standards for School Mathematics (1989), NRC Science Education Standards (1996), or AAAS's Project 2061 (AAAS, 1993), call for more 
efficient, effective multidisciplinary learning environments that are best developed in tight cycles of design, reflection, and redesign. Hard problems could link the largely unfocused curriculum in most U.S. schools identified in TIMSS to issues that concern all citizens (Schmidt et al., 1997). Public understanding of science is a national need, and materials for studying such hard problems are in demand for precollege courses.

Fourth, visualization and simulation tools empower students to continue to explore complex problems in subsequent courses and for their own edification. These tools help students become autonomous learners who can carry out projects more and more independently. By making tools available on the Internet, we can support lifelong learning in the context of these hard problems.

Research

The Theme Team began by inviting workshop participants representing projects with most or all of the following properties:

- Development and research of specific new applications for visualization and modeling including hands-on visualization and modeling tools, use of multiple representations for complex phenomena like the weather, and use of intermediate models to understand difficult concepts.

- Application of visualization and modeling to improving instruction in science, mathematics, engineering, or technology for students from kindergarten to Grade 14.

- Empirical investigations of the impact of visualization and modeling on standards-based learning outcomes.

- Interest in advancing understanding of technical and design issues necessary for creating powerful and useful tools, impacting students and teachers in broad and diverse settings (including home, school, museum, and community), and defining an instructional framework to guide developers of the next generation of innovations.

Nine partnerships were formed at the workshop: (1) Applying Lessons Learned: An Integrated Learning Environment; (2) Supporting Use of Video for Improving Teaching in On-Line Teacher Professional Development Networks; (3) Middle School Sciences; (4) Think Globally, Learn Locally; (5) Synthesis Of CILT Environments; (6) Sharing Assessment Models; (7) Virtual Museums; (8) Cocoa Dynamic Programming Environment; and (9) Scientists' Tools \& Distributed Learning.

These led to four CILT projects that are underway:

(1) Visualizing the Amazonian Rain Forest. (Project Leader: Douglas Gordin, formerly MSU, now SRI International). In a collaboration with Osiris Studios, two forms of visualization will be integrated and made mutually supporting for aiding students' inquiries concerning the complex ecosystem dynamics of the Amazonian Rain Forest. The visualization technologies to be used are Virtual Reality Modeling Language (VRML) and Geographic Information Systems (GIS) with satellite images.

(2) Virtual Reality Solar System (VRSS). (Project Leader: Kenneth Hay, U. Georgia). This project seeks to revolutionize astronomy education. It extends the VRSS Project, now an experimental undergraduate Astronomy course taught at Indiana University (IU) as a traditional lecture-based course, into a constructionist course at both IU and U.Ga. Students will build VR 
models of different aspects of the solar system in collaborative teams on high-end graphics computers. Development innovations include incorporating knowledge integration and learner collaboration support system into the course and innovations to incorporate primitives appropriate to conceptual understanding of the astronomy domain. Research will explore the impact of these new functionalities for student learning.

(3) Digital Weather Station (DWS). (Project Leader: Sasha Barab, Indiana University). The Digital Weather Station (DWS) is an exhibit at The Children's Museum of Indianapolis, with the aim of developing students' understanding of the weather as a three-dimensional system and their skills in the scientific process of visualization. The DWS runs on three high-end SGI workstations and utilizes an interface designed to enable young children to manipulate sophisticated, expert level scientific visualization tools. The tool supports learner's immediate creation of 3D interactive, dynamic visualization of standard weather parameters. These tools are not scaled down tools visualizing fictitious data; they are built on the same tools and data used everyday by scientists. The DWS team has designed and developed an innovative learner's interface that almost eliminates the technical and domain learning curve these tools create for novices. In their CILT project, the DWS team will develop inquiry-based and problem-based learning activities where the technology can visualize a 3D phenomenon. The CILT research program, also including Vanderbilt University collaborators, will explore groups of learners of diverse ages appropriating this tool as a new way of understanding meteorology in a variety of situations adopting various pedagogical strategies (i.e., open exploration, challenge questions, guided discovery, and anchored instruction).

(4) Exploring Self-Explanatory Simulators for Middle-School Science (Project Leader: Kenneth Forbus, Northwestern University (NWU), Department of Computer Science). Selfexplanatory simulators combine qualitative, conceptual explanations with numerical simulation. For example, a self-explanatory simulator can produce plots of the numerical values a parameter takes, like any traditional numerical simulator. But it can also summarize the behavior of the system in terms of conceptual events (i.e., liquid in a pot heating up for a while and then starting to boil) and explain the causal relationships that hold between the parameters (i.e., an increase in heat causes a change in temperature, until the boiling point is reached). Forbus et al. will explore the role of self-explanatory simulators in teaching middle-school science by creating a set of simulation activities to complement an existing curriculum. Linn and colleagues at Berkeley have developed a middle-school curriculum for learning about heat and temperature, and their longitudinal research suggests that what is learned is retained better than standard teaching methods. This project will create a complementary suite of activities using self-explanatory simulators for helping students learn about thermal phenomena. The focus will be on simulationbased lab activities, such as boiling fluids in various containers, so students can explore aspects of the phenomena that would otherwise be too dangerous, expensive, or tedious to do in realtime with physical systems. These activities and a modified version of Linn's curriculum will become the starting point for a Work Circle (involving NWU and Michigan researchers with personnel from the Chicago Public School system) for the development of a curricular unit to be used in the Chicago Public School system, starting in the 1999-2000 school year. The technology development of self-explanatory simulators is already under separate funding, from NASA Ames. 


\title{
Theme Team 2: Technology and Assessment Models
}

\author{
(Co-Directors: Professor John Bransford and Dr. Barbara Means)
}

Background.

Most U.S. science and mathematics classrooms continue to be dominated by hours devoted to memorizing vocabulary, facts, and set procedures (Schmidt et. al, 1997). An extensive body of research has documented the naive conceptions of learners that remain hidden in such classrooms (Smith, diSessa, \& Roschelle, 1993), as well as the "inert" nature of rotely learned facts and procedures (Cognition and Technology Group at Vanderbilt, 1990, 1992, 1997). Standardized tests often reinforce the "mile-wide, inch-deep" approach to curriculum, providing little insight into students' level of understanding.

In reaction to the deficiencies of conventional curricula and pedagogy, a growing number of classrooms are engaging in exciting project-based activities in mathematics and science (Hawkins, 1997; Krajcik et al., 1994; Means et al., 1993; Sandholtz et al., 1997). One of the biggest challenges faced by teachers in implementing such innovations is providing opportunities for frequent assessment of student learning. Without assessments that give insights into what individual students are learning through their activities, innovative projects can have disappointing results. For example, students can do extensive water monitoring without developing an understanding of the river they monitor as an ecosystem (Barron et al., 1998). Teachers need to assess student thinking, and changes in that thinking, if they are to successfully implement instruction aimed at conceptual growth.

It is well documented also that the nature and content of the assessments used in classrooms have a strong influence on what and how teachers teach (Herman \& Golan, 1991; Resnick \& Resnick, 1985). Most assessments are tests of remembering. Because diagnosing and assessing students' understanding of, and ability to apply, the important "big ideas" in science and mathematics is so important and so difficult to do well, technology supports for meaningful classroom assessments could provide great benefits for learning.

The Technology and Assessment theme encompasses technology-based mechanisms for supporting both formative (diagnostic) assessment and summative assessment to help students, teachers, school systems, and communities see qualities of student achievement that are invisible on traditional, standardized tests. Questions this theme team is considering include: How can network technology support the development and implementation of shared norms for assessing student work? How can network technology support measurement of what students have learned in ways that motivate students, produce further learning, and inform teacher practice? Can electronic archives of extended interactions between students and others or between students and software environments be catalogued and analyzed to produce cost-effective measures of learning and collaboration? Does changing the medium or type of assessment have a differential impact on girls, historically underserved groups, or students with disabilities? Can generalizable science inquiry learning metrics be developed that could be used across some range of projects? 
Research

The Technology Support for Assessment Workshop explored the need to assess student understanding and ability to use their knowledge and skills in new contexts, the multitude of uses made of assessments, and prototype technology-supported assessment tools. The goal of the workshop was to bring together expertise in education and technology to discuss assessment requirements, technology-supported approaches, and guidelines for effective and appropriate use of assessment information.

A number of workshop participants argued that assessment methods should go beyond looking solely at individual independent performance (e.g., Anderson et al., 1995). Many new instructional methods and computer environments are capitalizing on the benefits of extended, collaborative work to develop new knowledge. There is potential for creating domain tasks and assessments that capture students' development while working with others on group projects. It is also important to help students work on assessments that fit the kinds of activities they need for college and employment opportunities. Internet-based inventories of model assessments keyed to curriculum frameworks and national standards were described and discussed.

The workshop identified five areas for potential collaborations: (1) co-design of curriculum and instruction including self-assessment, (2) design framework for assessment, (3) exemplary assessments of students' learning in groups with technology devices, (4) "dream" assessment project, and (5) strategies to broaden public thinking about alternative assessments. As a result of these discussions, the following projects were reviewed, and accepted for funding.

(1) Aligning TIMSS Items with the NCTM Standards (Project Director: Kenneth Koedinger, Carnegie Mellon University, HCI Institute). Current studies of technology-rich instruction rarely use assessment items for which there is a clear public perception of importance. National standards efforts provide a way to assess what processes have been judged by education experts to be important. Also, the poor performance of US students on the Third International Mathematics and Science Study (TIMSS) has received wide public attention. If technology innovations can lead to dramatically improved performance on categories of items such as those in TIMSS, this should provide a clear message that such innovations do work and are worth pursuing. This project will review TIMSS items, develop a mapping to the NCTM standards, and provide a clear articulation of the targeted cognitive processes. Thus, it is critical to not only select TIMSS item categories that show where US students are lagging behind, but furthermore, to align these items with the NCTM standards to be clear about the underlying cognitive processes that are the true focus of instruction. Focusing on mathematics items in both the 8th and $12^{\text {th }}$ grade TIMSS assessments, this team will select items for which US students are lagging behind other countries, and a draft NCTM standards alignment document will be created that indicates the mappings behind items and standards. Once TIMSS items and NCTM standards have been aligned, the field can begin to select appropriate technology projects that can address these items, and design learning assessments that target the learning strategies and knowledge that students should be acquiring.

(2) Assessment and Technology Monograph (Project Directors: John Bransford and Barbara Means). The National Education Association (NEA) asked the CILT Assessment Team to prepare a book manuscript during 1998 on technology and assessment. The NEA will publish the finished book and distribute it to a broad segment of its membership including those 
responsible for professional development support at a regional level. NEA and CILT resources for producing the manuscript will be complemented by those of the Learning Consortium, a project organized by Vanderbilt University to use technology to improve teaching, learning, and assessment by uniting efforts among a number of groups including policy makers, leaders in school reform, and academic researchers. The plan is to discuss examples of technologyenhanced assessment approaches that exist in a number of "states" ranging from (a) interesting ideas that are just being developed; (b) existing prototypes that are ready for testing; and finally (c) finished products - including research products being used in classrooms and commercial products available on the market. We will also discuss the impact of current assessment practices on the promotion of technology (e.g., to what extent are some of these practices impeding the advancement of technology in schools?). This volume will serve as an early product discussing the assessment implications of cognitively oriented research on learning in technology-supported environments and is expected to pave the way for a larger, edited volume, possibly with a companion CD-ROM of promising prototype assessments.

\title{
Theme Team 3: Ubiquitous, Low-Cost Computing
}

\author{
(Co-Directors: Dr. Robert Tinker, Prof. Bob Brodersen)
}

\section{Background}

As learning technologies become ubiquitous over the next few years, the disparity between what could be taught making full use of technology and what is actually taught in most classrooms will be increasingly obvious and intolerable. The problem is that creating a new sequence for teaching is a massive effort that requires a better research base and extensive experience. One cannot experiment casually with what students should learn for fear of missing critical concepts or undermining student motivation. Yet, the research community that has created the possibility of vastly improved learning must undertake this work, or see its visions unrealized and the educational potential of technology unused.

Increased use of technology in inquiry is an educational strategy at the core of educational reform and is consistently reported by educators as the most difficult aspect of reform to implement (Sandholtz et al., 1997). Technology-based tools support inquiry by enhancing student ability to gather, display, and analyze data, to undertake collaborative inquiry, and to scaffold student learning from their investigations (Norman \& Spohrer, 1996). Making these tools portable could transform a variety of everyday contexts into learning opportunities in the home, street, field, bus, car and subway. Smart probes could greatly increase the quality of data gathered in student investigations. Wireless networking could bring the full resources of the Internet into these contexts (Kozma \& Schank, 1998). Basing this technology on massproduced, interoperable components could provide dramatic efficiencies of reuse, integration, and scale, making educational benefits available more equitably (Roschelle \& Kaput, 1996).

This theme focuses on exploring the learning opportunities ubiquity would create by scanning the technological horizons, anticipate implications for learning, and provide feedback to the marketplace. We also sponsor the development of prototype applications and affiliated learning research that exemplifies the potential payoff of alternative devices. Finally, we sponsor research on technology-enhanced curriculum strands that build on each other and could lead to major revisions in what is thought possible for typical learners to master. 


\section{Activities}

At the Ubiquitous Technologies workshop, participants defined six fertile, high-priority areas for potential CILT pilot partnership projects: (1) smart interfaces: the future low-cost devices; (2) infrastructure glueware and continuous computing; (3) webs and probes; (4) haptic devices for learning math and science; (5) mathematics, science and technology in elementary education; and (6) media case studies of ubiquitous computing in learning.

From these areas, the following three projects have been developed into CILT projects.

(1) Envisioning a Future Product Line of Low Cost Devices (Project Directors: Michael Mills, IDEO and Jeremy Roschelle, SRI International). The educational community needs a better understanding of the potential in the handheld space of "learning appliances." We can foresee the potential for the success of these devices in the phenomenal impact of graphing calculators and probeware. This multidisciplinary group will develop a set of concept sketches which should spark dialogue in our community, and draw the interest of potential research and manufacturing partners. The internationally-renowned design firm IDEO has a brainstorming process called a "deep dive" that results in highly communicative and innovative concept sketches in a very short time. This process was used to create bold, exciting, compact vision pieces, which will be posted to a web server where they could gain additional public commentary. Afterwards, we will use the sketches and commentary as web-based discussion starters with potential partners for follow-on projects aimed at realizing the vision.

(2) Sonic Ranger Application for the PalmPilot (Project Director: Stephen Bannasch, The Concord Consortium). Mobile field investigations by learners is a key functionality for ubiquitous computing. This project involves designing Palm computer software that exploits the educational advantages of portable low-cost devices equipped with sensors for field investigations. The sensor used is a motion detector with a built-in microcontroller. This feasibility study is designed a PalmPilot application and interface to the motion detector as an example of the many possibilities for interface applications to support learning with low-cost handheld devices.

(3) Using Haptic Devices to Learn Mathematics and Science (Project Director: Ricardo Nemirovsky, TERC). The field is increasingly aware of the role of bodily and kinesthetic activity in science and mathematics education, evidenced in the popularity of the motion detector not only in physics classes but in high school math. Force feedback could be a potential major form of engagement with mathematical symbols and scientific ideas; from mechanics to differential geometry, from chemical bonds to gravity. This project is investigating this educational potential by exploring the interplay between kinesthetic/bodily activity and math/science learning by using a new generation of tools with which the computer become sensitive to and generates forces. 


\title{
Theme 4: Tools for Learning Communities
}

\author{
(Co-Directors: Drs. Roy Pea and Jeremy Roschelle)
}

Background.

Significant innovation in education requires more than a focus on the local process of learning - we also need mechanisms for strengthening the community that surrounds each learner to maximize her or his learning potential (e.g., Brown \& Campione, 1990). Increasing the effectiveness of network-based collaboration will have huge implications for reshaping the content and pace of learning at all levels, as well as the role and identity of teachers. The educational potential of computers coupled with telecommunications has long been recognized (Harasim, 1990; Harasim et al., 1995; Hilz, 1990; Hunter, 1993; Riel \& Levin, 1990; Roberts, 1995). Collaborative learning can be established between peers anywhere, bring new human resources into learning (e.g., scientists, retirees, experts), and support these collaborations with a full range of technology-based tools. The implications for formal and informal student learning, for teacher professional development, and for support of educational R\&D are enormous.

With the extraordinary growth recently in "virtual universities," the "virtual classroom," and "distance learning," there is still a shortage of needed supports for collaborative learning processes. Much work on virtual universities and virtual precollege "campuses" inherits the teacher-centered, lecture-at-a-distance, information transfer model that "distance learning" has had for decades (Pea \& Gomez, 1992). This orientation will not be our focus. Instead, we base the efforts of our theme team on recent research in the social and cognitive sciences. This research highlights the pragmatics of supporting project-based, active inquiries in which students collaborate to construct meaning with local and distant peers, mentors, and guides (e.g., Pea, 1994; Roschelle, 1992). We anticipate new technologies supporting highly interactive learning conversation, mediated by complex symbolic representations, such as mathematical notations, scientific visualizations, and multimedia case studies. These technologies will draw jointly on powerful modeling tools and participants' informal sketches and annotations.

This strand has identified three main areas for development:

Shared Active Representation Tools: Beyond the General-Purpose Whiteboard. Shared Active Representations are a critical enabling technology for successful learning conversations locally and on-line about complex subject matter in mathematics and science. They include text, graphs, digital forms of student work products, mathematical notations, simulations and visualizations, gestural depictions, annotations, and even video streams of activity.

Shared active representations are important because learners and teachers require a common ground of conversational props that they can act on to make sense of a problem situation together. Highly interactive, multi-turned conversations with such mediating representations can support the construction of new understandings. Extensive and careful empirical work on the embodied and situated nature of learning interactions and discourse indicates that highly interactive and multimodal conversations around ever-changing "conversational props" are commonplace(e.g., Goodwin \& Heritage, 1990; Roschelle, 1992). When two or more people are learning together face-to-face, or when one or more learners are engaged interactively with a mentor or teacher, there is a rich interchange of graphical and verbal representations, and 
gestures and pointing and linguistic reference to aspects of these representations are fundamental parts of the process of interpretation and making of meaning. These representations made during learning interchanges become "layered" rather quickly, as annotations and other markings—such as circles and underscores-are used to direct the attention of other participants.

CILT is particularly interested in harvesting and organizing insights about tools for learning communities that will deepen our understanding about how to support highly interactive, mediarich interchanges in distributed learning communities. Beyond the shared whiteboards of many collaboration software environments, we are interested in other kinds of activity supports for symbolic expressions more complex than text or bitmap graphics diagrams, including states of active simulations (in which control can be exchanged among remote participants), mathematical notations that are linked to graphs that plot their expressions, and layering of annotations on such simulations and notations (e.g., Pea, Roschelle, DiGiano, Schank, \& Schlager, 1997). The messages that participants in communications using a shared whiteboard can construct need to be richer, with easy capacity for creating, editing, linking, and displaying drawings, equations, graphs, spreadsheets, and models. We will seek to learn how education might benefit from the concepts, models, and prototypes from business and science groupware applications, and the many emerging "collaboratories" (e.g., Cerf et al., 1993) and platforms for supporting collaborative scientific conversations. We are also concerned with understanding what is to be gained in the well-motivated use of shared video in these media-rich, networked interpersonal workspaces.

Community building tools: Beyond interest groups. "Community-building" tools are those supporting the Web's role in defining "social places" and "virtual worlds" for new kinds of interchanges. Examples include: (a) multi-user virtual environments (MUVEs, also called MUDs or MOOs); (b) community-based information filtering technologies such as user-profiling and recommendation engines, and (c) "intelligent agents" and other tools emerging in business and scientific applications for creating and sustaining knowledge networks. Another entry is (d) "metadata" projects, that aim to order instructional and learning materials by labeling them by types so that they can be sought out in forthcoming Web browsers (using XML, rather than HTML). How can technology better enable participants to find each other and form collaborative groups around mutual interests, skills, and needs?

Powerful distributed learning environments will need to augment the process of establishing social places (Harrison \& Dourish, 1996; Roseman \& Greenberg, 1996) in cyberspace, helping to support the formation and conduct of activities for communities of interest. Socializing is important not only important for building trust in teaching and in mentoring relationships faceto-face; richly textured virtual places will provide diverse activities in which teachers, mentors, and learners can get to know one another in deeper ways than text alone effectively supports. For example, participation in on-line communities offers a unique opportunity for teachers to expand their set of peers and to gain a sense of connection with a practicing community of educators, scientists, and science education researchers (e.g., Ruopp et al., 1993; Honey et al., 1994). The interactions involved in shared learning are more extensive and subtle than the typical tools for sharing information among interest groups; support is needed for long-term, supportive, structured relationships, not just casual exchange of tidbits, much less "push" media.

Graphically-oriented multi-user virtual environments from the gaming world (MUDs, MOOs) have been the basis of many adaptations for learning purposes, such as SRI's TAPPED 
IN on-line environment for teacher professional development (Schlager \& Schank, 1997). Virtual-world-building companies such as Worlds, The Palace, and Worlds Away are providing graphically rich and 3D social places in which people around the world represent themselves with "avatars" and interact at a distance-but learning and education thus far has not been a focus of these environments (Pea, in press-b). On another front, new research and commercial developments in "community-based" or "social" filtering technology harness the collective knowledge of all of a Web site's "customers" to make predictions for each individual visiting the site. These social filtering tools use profiling information supplied by participants in order to make recommendations concerning resources others "like them" have found useful. Might these tools prove extensible from interest groups to learning groups? Finally, diverse organizations (including the U.S. Department of Defense and the White House Office of Science Technology and Policy) are engaged with EduCom's IMS Project to further the development of a common, open-access technical framework of metadata and prototype systems for coding on-line learning materials. The planned release in 1998 of new Web browsers designed to allow coding and search of metadata fields for Web pages, and the emergence of metadata coding for Web materials together offer the opportunity of bringing unprecedented order to on-line educational resources. We conjecture that metadata for learning resources will provide important support for distributed learning communities.

Socio-Cognitive Structuring Tools: Beyond Scaffolding. The third class of tools involves organizing patterns of activity with SharedActiveReps in learning communities to enhance learning. Throughout history, great teachers have created participation structures and progressive sequences that engage learners in posing questions, deep thinking, seeking diverse viewpoints, creating argumentation, supporting reflection and revisions in thinking, and offering frequent feedback and guidance toward higher standards. The Socratic dialogue offers one famous example in which students learn through progressive questioning from an expert. More recent social science and cognitive research have uncovered successful patterns in tutorial, mentoring, and group discussion interactions. Recognizing that typical chat and bulletin board systems do not organize conversation sufficiently for learning, researchers have created tools like CSILE (Scardamalia \& Bereiter, 1994), the Knowledge Integration Environment (Linn, Bell \& Hsi, in press) and CoVis (Pea et al., 1997). These tools all "scaffold" learning by prestructuring the kinds of contributions learners can make, supporting meaningful relationships among those contributions, and guiding students' browsing based on the basis of socio-cognitive principles.

CILT is very interested in integrating the insights from these types of tools and related research into more widely available products that incorporate Shared active representations and Community Building support. At the same time, we are aware that successful learning does not always fit the predefined categories supported in such tools, and does not always follow preidentified patterns. Thus, we seek ideas for moving beyond the scaffolding of contributions and relationships, to tools that allow teachers and students to dynamically and reactively structure their history of interactions so as to maximize future learning opportunities. For example, we need the ability to capture a session history as students work with shared active representations, so that the session can later be replayed for reflection to encourage higher-order learning in which students become aware of their own process of constructing knowledge. How can we best capture and extract the critical moments from learning activities? 
Research

Participants at the workshop selected seven partnership project concepts: (1) framework for discourse and capture of shared active representations, (2) a testbed for shared active representations, (3) model teacher professional development consortium, (4) communities members' knowledge network: (5) common framework for learning community tools, (6) reform threshold group, (7) foundations reading group on "learning communities."

Since the TLC workshop was conducted, three project proposals have been launched.

(1) Development of the Requirements for a Common Framework for Collaborative Learning Community Tools (Project Director: Geoffrey Fox, Syracuse University). Most of the standards processes such as IMS and IEEE now occurring for educational components are targeted at higher education or, as in the ADL (Advanced Distributed Learning) initiative, Defense Department training requirements. This CILT group has defined a 8-10 month process involving several workshops and public forums that will be used to develop a draft reference document for public review. Its aim is to characterize requirements for tools and systems that support and enable the creation of synchronous and asynchronous collaborative learning communities that are pedagogically and community inclusive, but with special attention to the particular needs of K-14 education, including synchronous and asynchronous collaboration.

(2) ICSAR: Interoperable Components for Shared Active Representations (Project Director: Dan Suthers, University of Hawaii, Dept. of Information and Computer Sciences). The longrange vision of this group is a set of re-usable interoperable components for simulation, animation, graphing, annotation, anchoring discussions, displaying evidence and connecting tools and tutors. As first steps, they may develop scenarios that require such interoperability, to better understand the nature of the problem. They will try to move to a proposal for a testbed to examine the practical details of educational component software. This diverse group of collaborators will perform preliminary needs analyses and prepare for further funding.

(3) CILT Knowledge Network (Project Directors: Marie Bienkowski and Roy Pea). There is no simple way to find out answers to questions like: Who are the learning technology researchers? What projects are they working on? What reports are available about their findings? Where are the different labs working on learning technologies, and what are the major conferences and journals? Where would I go for graduate training in this field? What are the innovations underway in the field, and where is it headed? What are the findings on what works in integrating learning technologies into education, or homes? What are innovating teachers learning from integrating technology into instruction? Currently there is no coherent community support for these inquiry needs, and at best, a highly splintered infrastructure. The CILT Knowledge Network will not primarily be a digital library, but a social place in which people come to communicate what they are learning about how to advance education with new learning technologies. This work will begin under CILT theme team support and then seek additional grant support. 


\section{CILT Programs}

In this section, we characterize the CILT programs that contribute to the overall mission of the Center: an Industry Alliance Program, a School Partners Program, and our Communications Program.

\section{CILT School Partner and Associates Program}

The goal of the CILT School Partner and Associates Program is to link the CILT project closely to schools. We are establishing two-way relationships so that our research agenda is shaped by real problems in real schools and so the results of our research are adapted to school needs and widely disseminated. We will do this on a national basis with schools and organizations that are innovators in MST educational technology and that represent the realities of a cross-section of all U.S. schools.

We have identified two levels of interaction: Partner Districts and Associate Schools. Partner Districts are all innovators in educational uses of technology. They have identified project coordinators on staff to coordinate CILT activities. Many of them are close to one of the CILT founding organizations and have ongoing R\&D with members of the CILT community. These Partner Districts represent a broad cross-section of American education with a strong representation of schools serving less-advantaged students, both urban and rural.

In addition, 70 other LEAs have been invited to be CILT Associates. These districts and schools are participating in existing projects such as Concord's Virtual High School or INTEC programs (25 schools) or Pea and Gomez's CoVis Project (45 schools, most with T- 1 network connectivity). Thus, these schools have significant technology infrastructure and an appreciation for the ways in which research participation can support their education agendas.

Teachers in Partner districts will be involved in our research, and will co-author papers and related curricula. Online short courses will be developed as a means of sharing research techniques and findings among the teachers and researchers.

\section{CILT Industry Program}

As we have developed the CILT R\&D themes and individual/organizational intellectual resources, we have identified appropriate industry allies for mutually beneficial relationships with the Center from these key computing and communication industries market sectors: (1) hardware (personal computers, servers, small mobile computers, networking hardware-modems to switches); (2) software (server, tool, authoring applications); (3) network service providers; (4) content and activity providers (education, information, entertainment, shopping); (5) enabling services (electronic commerce, directory services, Web tracking); and (6) system integrators. In our experience, cost-sharing of Center support needs to develop collaboratively out of joint planning activities conducted by Center leadership and industry leaders. 
In its first year CILT ${ }^{4}$ has developed plans, strategies, legal agreements and marketing materials to promote the CILT Industry Alliance. The emerging two-tier Industry Alliance Program is designed to advance CILT goals and provide additional project funding and instrumental in-kind resources. CILT agreements with a core group of 4 to 8 companies as Senior Partners should be completed in the third quarter of 1998; a large group of Associate Partners is also likely. Participating corporations are electing to contribute to the substantive work of the Center through diverse forms of support (e.g., funds, designated staff-on-loan, equipment) while benefiting from commercialization prospects of Center developments and intelligence from the field, better understanding of the education marketplaces, public relations, and Advisory Board involvement. NSF funding for CILT provides seed support for an initial period of four years and is the basis for a significant opportunity for interested companies to become involved in the CILT Industry Alliance Program. The CILT Industrial Alliance Program offers industries the opportunities to reap the benefits of the Center's wide range of focused research and development efforts, and to increase the likelihood for technology transfer.

\section{CILT Communications: From Web Site to Knowledge Network}

In pursuing our goals of appropriately serving the learning technology research community that we are networking, we have been designing both information and social structures and strategies. Throughout our CILT invitational workshop activities and partnership project development, we have uncovered fundamental needs for a different effort than the CILT Web site originally planned. In our initial conception, we proposed CILT "dissemination activities" to include a comprehensive Web site to promote CILT activities and make information and tools readily available. We noted that the CILT Web site would be linked to other high-quality learning technology Web sites to promote the wide dissemination of information and provide ready access to CILT-affiliated resources and staff. We also indicated that we would "explore more cutting-edge approaches to bringing our Web-based resources to the attention and use of stakeholder audiences," including social information filtering, and notification services of relevant information by email according to Web site visitor's profiles filled out when they register at our site.

CILT has the aim of developing for widespread use the first national knowledge network for learning technologies. Our long-term vision of this knowledge network and its affiliated networking activities is a coordinated web of organizations, individuals, industries, schools, foundations, government agencies and labs. The network communications revolution has made possible such coordination, and holds considerable promise for scaling up the quality of research and its influences on educational practices and learning technologies product development. CILT networking is devoted to the production, sharing and use of new knowledge about how learning technologies can dramatically improve the processes and outcomes of learning and teaching. We are inspired by the extraordinarily rapid growth and perceived utility of the knowledge generated not only in scientific collaboratories but by popular networked

\footnotetext{
${ }^{4}$ We'd like to thankfully acknowledge Donna Baranski-Walker for her many contributions to developing the CILT
} Industrial Alliance Program as its Director in 1998. 
communities such as amazon.com, where reader-contributed book reviews have provided a highly popular new kind of learning resource-peer reviews rather than expert reviews. Pea (1998, in press-a) has examined the implications of these and other developments for educational research and its developing a more integral relationship to practice.

\section{Conclusion}

We have highlighted the challenges facing American education as it seeks to foster improvements in education with learning technologies - the need for innovation in the face of increasing complexity and diversity in forms of computing and communications available for learning, the need for broadly-based partnerships to catalyze breakthroughs, the overly-isolated nature of stakeholder groups, and the importance of coordinating and leveraging field-initiated R\&D toward innovations and breakthroughs. CILT provides a national center that aims to be responsive to these concerns. The crucial features of our Center design for advancing educational reforms aided by technologies are:

- Inclusiveness of diverse researchers, stakeholders, schools, and learners;

- Synergies created by establishing R\&D theme-focused virtual communities that leverage other activities and developments;

- Breadth of substantive contributions by focusing on R\&D themes with the greatest potential for breakthroughs to generate long-term learning gains.

The strategies and community-building mechanisms that are underway in our agenda for CILT will only work practically if there are many contributors to the CILT knowledge network outside of its four founding organizations. In our theme team efforts for CILT to date, we have begun engaging the collaborative efforts of educators, computer scientists and engineers, education researchers, cognitive scientists, and subject matter experts throughout the country. The seeds of this process are already underway in the community building and resource aggregation and structuring taking place at the CILT web site. We welcome wide collaboration, partnerships, and insights as we grow this knowledge network enterprise. 


\section{Bibliography}

AAAS (American Association for the Advancement of Science). (1993). Benchmarks for science literacy. New York: Oxford University Press.

Anderson, J. R., Corbett, A. T., Koedinger, K., \& Pelletier, R. (1995). Cognitive tutors: Lessons learned. The Journal of Learning Sciences, 4,167-207.

Barron, B. J., Schwartz, D. L., Vye, N. J., Moore, A., Petrosino, A., Zech, L., Bransford, J. D. \& CTGV. (1998, in press). Doing with understanding: Lessons from research on problem and project-based learning. Journal of Learning Sciences.

Brown, A. L. \& Campione, J. C. (1990). Communities of learning and thinking: Or a context by any other name. In D. Kuhn (Ed.), Contributions to Human Development, 21, 108-125.

Cerf, V. G., et al. (1993). National collaboratories: Applying information technologies for scientific research. Washington, DC: National Academy Press.

Chubin, C., \& Malcom, S. (1996). Policies to Promote Women in Science, In C-S. Davis, A.B. Ginorio, C.S. Hollenshead, B.B. Lazarus, P.M. Rayman and Associates (Eds.), The Equity Equation: Fostering The Advancement of Women in the Sciences, Mathematics, and Engineering (pp. 1-28). San Francisco: Jossey-Bass, 1996.

Cognition and Technology Group at Vanderbilt. (1990). Technology and the design of generative learning environments. Educational Technology, 31 (5) 34-40.

Cognition and Technology Group at Vanderbilt. (1992). The Jasper experiment: An exploration of issues in learning and instructional design. Educational Technology Research and Development, 40(1), 65-80.

Cognition and Technology Group at Vanderbilt (1997). The Jasper Project: Lessons in Curriculum, Instruction, Assessment and Professional Development. Mahwah, N.J.: Lawrence Earlbaum Associates,.

Dede, C., Salzman, M., \& Loftin, B. (1996). The development of a virtual world for learning Newtonian mechanics. In P. Brusilovsky, P. Kommers, and N. Streitz, Eds., Multimedia, Hypermedia, and Virtual Reality.

Forbus, K., \& Whalley, P. B. (1994). Using qualitative physics to build articulate software for thermodynamics education Proceedings of the 12th National Conference on Artificial Intelligence. 
Gomez, L., Fishman., B., \& Pea, R. (1998, in press). The CoVis Project: Building a large scale science education testbed. Interactive Learning Environments. (Special issue on telecommunications in education.)

Goodwin, C., \& Heritage, J. (1990). Conversation analysis. Annual Review of Anthropology, 19, 283-307.

Gordin, D., \& Pea, R. D. (1995). Prospects for scientific visualization as an educational technology. J. of the Learning Sciences, 4(3), 249-279.

Greeno, J., Collins, A., \& Resnick, L. B. (1996). Cognition and learning. In R. Calfee and D. Berliner (Eds.), Handbook of Educational Psychology.

Hagel, J. III, \& Armstrong, A. G. (1997). Net.gain: Expanding markets through virtual communities. Boston, MA: Harvard Business School Press.

Harasim, L. M. (1990). (Ed.) On-line education: Perspectives on a new environment. New York: Praeger.

Harasim, L., Hiltz, S. R., Teles, L. \& Turoff, M. (1995). Learning networks. Cambridge, MA: MIT Press.

Harrison, S. \& Dourish, P. (1996). Re-place-ing space: The roles of place and space in collaborative systems. In Proceedings of the Conference on Computer-Supported Cooperative Work (pp. 67-76), New York: Association for Computing Machinery.

Hawkins, J. (1997). The National Design Experiments Consortium: Final Report. New York: Center for Children and Technology, Educational Development Center.

Herman, J., \& Golan, S. (1991). Effects of standardized testing on teachers and learning: Another look (Tech. Rep. No. 334). Los Angeles: University of California, Center for the Study of Evaluation

Hestenes, D. (1987) A modeling theory of physics instruction. American Journal of Physics, 53, 1056-1065.

Hiltz, S. R. (1990). Evaluating the virtual classroom. In L. M. Harasim (Ed.), On-line education: Perspective on a new environment (pp. 133-183). New York: Praeger.

Honey, M., Bennett, D., Hupert, N., Kanze, B., Meade, T., Panush, E. M., Powell, K., Spielvogel, R., Dubitsky, B., Cohen, M., Melnick, H., \& Peterson, L. (1994). The Mathematics Learning Forums online: Using telecommunications as a tool for reflective practice. Machine-Mediated Learning, 4(2-3), 163-176. 
Horwitz, P., \& Barowy, W. (1994). Designing and Using Open-Ended Software to Promote Conceptual Change. Journal of Science Education and Technology, 3, 161-185

Huberman, B. A., \& Kaminsky, M. (1996). Beehive: A system for cooperative filtering and sharing of information. Technical Report, Xerox Palo Alto Research Center, Palo Alto, CA.

Hunter, B. (1993, October). NSF's networked testbeds inform innovation in science education. T.H.E. Journal, 21, 96-99

Jackson, S. L.; Stratford, S. J.; Krajcik, J.; Soloway, E. (1996, April). A learner-centered tool for students building models. Communications of the ACM, 39(4), 48-49.

Kaput, J. (1992). Technology and mathematics education. In D. Grouws (Ed.) A handbook of research on mathematics teaching and learning. NY: MacMillan, 515-556.

Kozma R., \& Schank, P. (1998). Connecting with the twenty-first century: Technology in support of educational reform. In D. Palumbo and C. Dede (Eds.), Association for Supervision and Curriculum Development 1998 Yearbook: Learning and Technology.

Krajcik, J. S., Blumenfeld, P. C., Marx, R. W., \& Soloway, E. (1994). A collaborative model for helping teachers learn project-based instruction. Elementary School Journal, 94, 483-497.

Linn, M. C. (1997). Designing computer learning environments for engineering and computer science: The scaffolded knowledge integration environment. Journal of Science Education and Technology.

Linn, M. C., Bell, P. \& Hsi, S. (in press). Lifelong Science Learning on the Internet: The Knowledge Integration Environment. Interactive Learning Environments.

Linn, M. C., diSessa, A., Pea, R. D., \& Songer, N. B. (1994, March). Can research on science learning and instruction inform standards for science education? Journal of Science Education and Technology.

Maltz, D., \& Ehrlich, K. (1995). Pointing the way: Active collaborative filtering. In Proceedings of CHI95, Computer Human Interaction, pp. 202-209.

McKinsey \& Company, Inc. (1996). Connecting K-12 schools to the information superhighway: Report to the National Information Infrastructure Advisory Council. Palo Alto, CA: McKinsey \& Company, Inc.

Means, B., Blando, J., Olson, K., Middleton, T., Morocco, C. C., Remz, A. R., Zorfass, J. (1993). Using technology to support educational reform. Washington, DC: U.S. Government Printing Office. 
NCTM (1989). Curriculum and Evaluation Standards for School Mathematics. Reston, VA: National Council of Teachers of Mathematics.

National Research Council (1996). The National Science Education Standards. Washington, DC: National Academy Press.

National Science Foundation (NSF). (1996). The Dynamic partnerships: Seeding and sustaining education reform conference. NSF: Washington, DC.

Norman, D.A, and Spohrer, J.C. (1996). Learner-centered education. Communications of the ACM, 39(4), 24-27.

Office of Science and Technology Policy (1997 April). Science and Technology: Shaping the Twenty-First Century. Report to Congress. Washington, DC: Office of the President.

PCAST (President's Committee of Advisors on Science and Technology). (1997). Report to the President on the Use of Technology to Strengthen K-12 Education in the United States. Panel of Educational Technology. (www.whitehouse.gov/WH/EOP/OSTP/ NSTC/PCAST/k-12ed.html.)

Pea, R. D. (1992). Augmenting the discourse of learning with computer-based learning environments. In E. de Corte, M. Linn, \& L. Verschaffel (Eds.), Computer-based learning environments and problem-solving_(NATO Series, subseries F: Computer and System Sciences). New York: Springer-Verlag GmbH (pp. 313-343).

Pea, R. D. (1994). Seeing what we build together: Distributed multimedia learning environments for transformative communications. Journal of the Learning Sciences, 3(3), 283-298.

Pea, R.D. (1998, in press-a). New communication forums for improving educational research and practice. Chapter for three-volume work by the National Academy of Education, Commission for Improving Educational Research.

Pea, R. D. (1998, in press-b). Distributed intelligence and the growth of virtual learning communities over the global Internet. PC97 Keynote Address, Kyoto, Japan, Council for Improving Educational Computing. (Translation in Japanese).

Pea, R. D., \& Gomez, L. (1992). Distributed multimedia learning environments: Why and how? Interactive Learning Environments, 2(2), 73-109.

Pea, R.D., Gomez, L. M., Edelson, D.C., Fishman, B. J., Gordin, D. N., \& O’Neill, D. K. (1997). Science education as a driver of cyberspace technology development. In K. C. Cohen (Ed.), Internet links for science education. (pp 189-220). New York, NY: Plenum Press. 
Pea, R. D., Roschelle, J., DiGiano, C., Schank, P., \& Schlager, M. (1997, December 13). A flying circus on the collaborative tailoring of educational objects. Videotape of invited plenary session of the Third International Conference on Computer Supported

Collaborative Learning (CSCL '97). University of Toronto/OISE, Canada. Springfield, IL: Center for Educational Television (60 minutes).

Reiner, M., Pea, R. D., \& Shulman, D. (1995). The impact of simulator-based instruction on the diagramming of the interaction of light and matter by introductory physics students. Journal of Science Education and Technology, 4 (3), 199-226.

Resnick, D. P., \& Resnick, L. B. (1985). Standards, curriculum, and performance: A historical and comparative perspective. Educational Researcher, 14 (4), 5-20.

Resnick, P., Iacovou, N., Sushak, M., Bergstrom, P., \& Riedl, J. (1994). GroupLens: An open architecture for collaborative filtering of NetNews. Proceedings of the CSCW 1994 Conference.

Riel, M. \& Levin, J., (1990). Building Electronic communities: Successes and failures in computer networking, Instructional Science, 19, 145-169.

Riley, R. W., Kunin, M. M., Smith, M. S., \& Roberts, L. G. (1996, June 29). Getting America's Students Ready for the 21st Century: Meeting the Technology Literacy Challenge-- A Report to the Nation on Technology and Education. Washington, DC: U.S. Department of Education. (http://www.ed.gov/ Technology/Plan/NatTechPlan/ title.html)

Roberts, L. (1995, May). (Ed.). The future of networking technologies for learning. (http://www.ed.gov/ Technology/Futures). Washington, DC: U.S. Department of Education, Office of Educational Technology.

Roschelle, J. (1992). Learning by collaborating: Convergent conceptual change. Journal of the Learning Sciences, 2(3), 235-276.

Roschelle, J. \& Kaput, J. (1996). Educational software architecture and systemic impact: The promise of component software. Journal of Educational Computing Research, 14(3), 217228.

Roseman, M. \& Greenberg, S.(1996). TeamRooms: Groupware for shared electronic spaces. Human Factors in Computing Systems CHI '96 Conference Companion, 275-276. New York, NY: Association for Computing Machinery.

Ruopp, R., Gal, S., Drayton, B., \& Pfister, M. (Eds.). (1993). LabNet: Towards a community of practice. Mahwah, NJ: Lawrence Erlbaum.

Russell, J., \& Kozma, R. (1994). 4M:Chem - Multimedia and Mental Models in Chemistry. Journal of Chemical Education, 71, 669-670. 
Sandholtz, J.H., Ringstaff, C, \& Dwyer, D.C. (1997). Teaching with technology: creating student-centered classrooms. NY: Teachers College Press.

Scardamalia, M., \& Bereiter, C. (1994). Computer support for knowledge-building communities. The Journal of the Learning Sciences 3(3), 265-283.

Schlager, M. S., \& Schank, P.K. (1997). TAPPED IN: A New On-line Teacher Community Concept for the Next Generation of Internet Technology. In Proceedings of CSCL '97, The Second International Conference on Computer Support for Collaborative Learning, pp. 230-241.

Schmidt, W. H., McKnight, C. C., \& Raizen., S. (1997). A splintered vision: An investigation of U.S. Science and Mathematics Education. Boston: Kluwer.

Shardanand, U., \& Maes, P. (1995). Social information filtering: Algorithms for automating "Word of Mouth." In Proceedings of CHI95, Computer Human Interaction, pp. 210-217.

Shulman, L. S. (1987). Knowledge and teaching foundations of the new reform. Harvard Education Review, 57(1), 1-22.

Smith, J. P., diSessa, A. A., Roschelle, J. (1993). Misconceptions reconceived: A constructivist analysis of knowledge in transition. Journal of the Learning Sciences, 3(2), 115-163.

U.S. Congress, Office of Technology Assessment (1995, April). Teachers and technology: Making the connection. Washington, DC: U.S. Government Printing Office.

White, B.Y. (1993). ThinkerTools: Causal models, conceptual change, and science education. Cognition and Instruction, 10(1), 1-100. 